\title{
O SISTEMA SUBTERRÂNEO DE DIOSCOREA KUNTHIANA ULINE EX R. KNUTH (DIOSCOREACEAE)
}

\author{
DALVA CASSIE ROCHA* \& \\ NANUZA LUIZA DE MENEZES**
}

* Universidade Estadual de Ponta Grossa, Pça. Santos Andrade, s.n.”, 84.100-970 - Ponta Grossa, PR, Brasil. e-mail: derocha@uepg.br
*: Instituto de Biociências, Universidade de Sĩo P’aulo. Cx. Postal 11.461, 05422-970, São Paulo, SP, Brasil. e-mail: nanuza@ib.usp.br

\begin{abstract}
The subterranean system of Dioscorea kunthiana Uline ex R. Knuth (Dioscoreaceae) The various species of Dioscoreaceae family are well known throughout the world as yams. The genus Dioscorea is most widely distributed and most common in the Americas. Its cconomic importance as a food source is based on the subterranean organs, in general considered to be tuberous structures. The subterrancan system of D. kunthiana has a cauline anatomy and is composed of a non-thickened stem axis and various tuberosities. The roots of the plant arise exclusively from these tuberosities. It is thus concluded that this subtcrianean stem does not act only as a food storage but functions mainly transporting water and nutrients from the roots to the aerial axis of the plant. These subterrancan stcms camnot be considered tubers nor rhizomes but rhizophores and constitute a second stem system in the plant.
\end{abstract}

\begin{abstract}
Resumo - (O sistema subterrâneo de Dioscorea kunthiana Uline ex R. Knuth (Dioscoreaceae)) Muitas espécies da família Dioscoreaceae são conhecidas no mundo todo como inhame. O gênero Dioscorea é o mais amplamente distribuido e comum no continente americano. O potencial econônico como fonte de alimento é devido aos órgãos subterrâneos espessados, na maioria das vezes chamados de tubérculos. O sistema subterrâneo de D. kunthiana é, em grande parte, de estrutura caulinar, composto de um eixo não espessado c varias tuberosidades das quais partem todas as raízes da planta. Concluiu-se então, que este caule subterrâneo não é apenas um órgão de reservas nutritivas mas tem como função principal transportar água $\mathrm{e}$ nutrientes das raaízes à porção aérea da planta. Aclmitiu-se que este caule subterrâneo não deveria ser chamado de tubérculo nem de rizoma, mas sim de rizóforo e se trata de um segundo sistema caulinar presente na planta.
\end{abstract}

Key words: Sistema subterrâneo, caule subterrâneo, rizóforo, Dioscoreaceac.

\section{Introdução}

Na família Dioscoreaceae, Dioscorea é o maior gênero em número de espécies e também o mais amplamente distribuído no mundo (Ayensu 1972). Em muitas espécies que possuem órgãos subterrâneos espessados, estes são consumidos como alimento, representando grande potencial econômico (Chu \& Figueiredo-Ribeiro 1991).

Com espécies brasileiras, destacam-se os trabalhos sobre anatomia foliar (Barroso et al. 1974), germinação de sementes (Vianna \& Felippe 1986 e 1990, Ladeira $e t$ al. 1992), fisiologia do crescimento e desenvolvimento (Vianna \& Felippe 1984), cultura in vitro (Vianna \& Mantel 1989) e composição bioquímica (Chu \& Figueiredo-Ribeiro 1991).

Um dos mais antigos trabalhos sobre morfologia interna e externa de Dioscoreaceae foi realizado por Goebel (1905). Trata-se de um importante trabalho que procurou questionar a verdadeira identidade das estru- turas tuberizadas, investigando principalmente a sua natureza. Infelizmente, poucos autores que se seguiram trabalhando com Dioscoreaceae, mencionam este trabalho. Nele, Goebel refere-se às estruturas tuberizadas de algumas espécies do gênero Dioscorea como órgãos intermediários entre raiz e caule.

Outros trabalhos mais recentes trouxeram valiosas contribuições para a compreensão das estruturas subterrâneas de Dioscoreaceae. Nesses, tubérculo e rizoma são as denominações mais usadas para o sistema subterrâneo na família (Burkill 1960, Ayensu 1972, Teichman und Logischen et al. 1977, Wickham et al. 1981, Teichman und Logischen \& Robbertse 1981).

No Brasil, numa primeira fase, foram realizados estudos morfológicos sobre órgãos subterrâneos principalmente com plantas de cerrado (Rizzini \& Heringer 1962, Rizzini 1965, Rizzini \& Heringer 1966). Com o reconhecimento de que a classificação destes órgãos baseada apenas na morfologia mostrava-se insuficiente, teve início uma nova fase na qual as investigações vêm 
sendo realizadas também sob o ponto de vista anatômico (Menezes et al.1969, Figueiredo 1971, Paviani 1972, Sajo \& Menezes 1986).

O objetivo do presente trabalho é analisar morfoanatomicamente as estruturas caulinares de uma espécie do gênero Dioscorea para elucidar a natureza dos órgãos subterrâneos.

\section{Material e métodos}

A espécie D. kunthiana Uline ex R. Knuth ocorre em matas ciliares na Serra do Cipó, no Estado de Minas Gerais localizada na Cadeia do Espinhaço (Corrêa 1926, Giulietti et al. 1987). A identificação do material coletado foi feita por Gilberto Pedralli (CETEC-MG) e as exsicatas encontram-se no herbário do Instituto de Biociências da Universidade de São Paulo (SPF 70812 e SPF 73031).

O material coletado foi fixado em solução de F.A.A. $50 \%$ ou Etanol $70 \%$ (Johansen 1940).

Os cortes à mão livre e incluídos em parafina (Johansen 1940) foram submetidos ao processo de dupla coloração com fucsina básica $0,5 \%$ e azul de alcian $1 \%$ ou azul de astra $0,5 \%$ (Souza et al. 1995).

Para detecção de mucilagem dos canais secretores, utilizou-se azul de metileno e vermelho de rutênio (Langeron 1949); para verificação do oxalato de cálcio utilizou-se nitrato de prata e água oxigenada (Silver \& Prince 1969); para a detecção do amido utilizou-se lugol (Johansen 1940).

As fotomicrografias foram realizadas com o auxílio de um fotomicroscópio Olympus, Vanox (Processo Fapesp 81-0088-2).

\section{Resultados}

Embora tenham sido apresentados os desenhos referentes a três plantas (Fig. 1A, B e C) todo o estudo foi baseado em grande número de plântulas coletadas nas matas ciliares da Serra do Cipó.

Na figura 1A está representada uma planta jovem inteira de D. kunthiana. O ramo aéreo é volúvel, pode atingir vários metros e é, freqüentemente, único ou pouco ramificado, cilíndrico e com algum espessamento em regiões nodais. As folhas são pecioladas, alternas, base do limbo cordiforme, ápice acuminado e venação curvinérvea, reticulada. É possível observar que, a partir do nó cotiledonar no nível do solo (seta a), cresce um eixo caulinar ( $\mathrm{Ri}$ ) verticalmente para dentro do solo. Trata-se de um ramo delgado e aclorofilado que, de espaço em espaço, forma estruturas tuberizadas (Rit). O nó cotiledonar apresenta uma espécie de genículo, devido a um desvio no eixo da planta.
Na figura $1 \mathrm{~B}$ está representada apenas uma parte do sistema subterrâneo de um indivíduo adulto. O ramo subterrâneo rompeu-se ao ser removido do solo durante a coleta devido a sua fragilidade. Apesar dessa fragilidade, esse eixo alcançava cerca de um metro de profundidade. Nele pode-se observar várias dessas estruturas espessadas (Rit) de onde partem todas as raízes que a planta apresenta.

O sistema subterrâneo, que atinge profundidades diferentes em diferentes plantas, é sempre finalizado por uma dessas estruturas tuberizadas (Rit.), que se aprcsentam achatadas dorsiventralmente com nítidos nós e internós como mostra a figura $1 \mathrm{~A}$. O nó cotiledonar encontra-se protegido por um catafilo (Fig. 1B - Ca), provavelmente, de origem cotiledonar.

A figura $1 \mathrm{C}$ representa uma plantas formada a partir de uma tuberosidade, não se notando catafilos nem desvio do eixo caulinar no nível do solo (Ns), de onde sai a folha.

As figuras 2A- D correspondem ao caule aéreo não espessado, numa região mais próxima do ápice (Fig. A e B) e numa região distal (Fig. C e D). Nas figuras $2 \mathrm{~A}$ e 2C nota-se o córtex formado por uma estreita camada de células. Nas figuras $2 \mathrm{~B}$ e $2 \mathrm{C}$ é possível distinguir, nitidamente, a endoderme (En) e o periciclo (Pe), este último formado por uma ou duas camadas de células com paredes fortemente espessadas. Observa-se, também, um cilindro vascular com uma disposição de feixes menores intercalados com feixes maiores. Na região mais jovem do caule os feixes vasculares apresentam-se pouco desenvolvidos em relação àqueles observados no caule adulto. Os elementos de protoxilema ( $\mathrm{Px})$ estão voltados para a medula evidenciando a diferenciação endarca do xilema. O floema ocupa duas posições (Fig. 2D- F1 e F2) entre grandes elementos de metaxilema $(\mathrm{Mx})$ e ainda nos floemas interno e externo, notam-se canais secretores (Cs).

Nas figuras 3A e 3B estão representadas secções transversais da planta na região do nó cotiledonar. Observa-se um catafilo (Ca), na região de ligação do eixo aéreo (seta) com o eixo subterrâneo não espessado (Ri). Na figura 3B é possível distinguir duas gemas caulinares endógenas $(G)$ e o espaço vazio deixado por uma outra que se destacou no momento do corte.

As figuras 4A-D representam a porção caulinar subterrânea não espessada $(\mathrm{Ri})$ correspondente à região abaixo do nó cotiledonar indicada na figura 1B. A organização estrutural é semelhante àquela vista na porção aérea, isto é, com protoxilema (Px) endarco. Entretanto, na figura 4A é possível notar o córtex com um maior número de camadas do que na porção aérea que se vê na figura 2. O floema também se apresenta dividido em duas unidades nos feixes desenvolvidos, nesta porção caulinar subterrânea não espessada. 


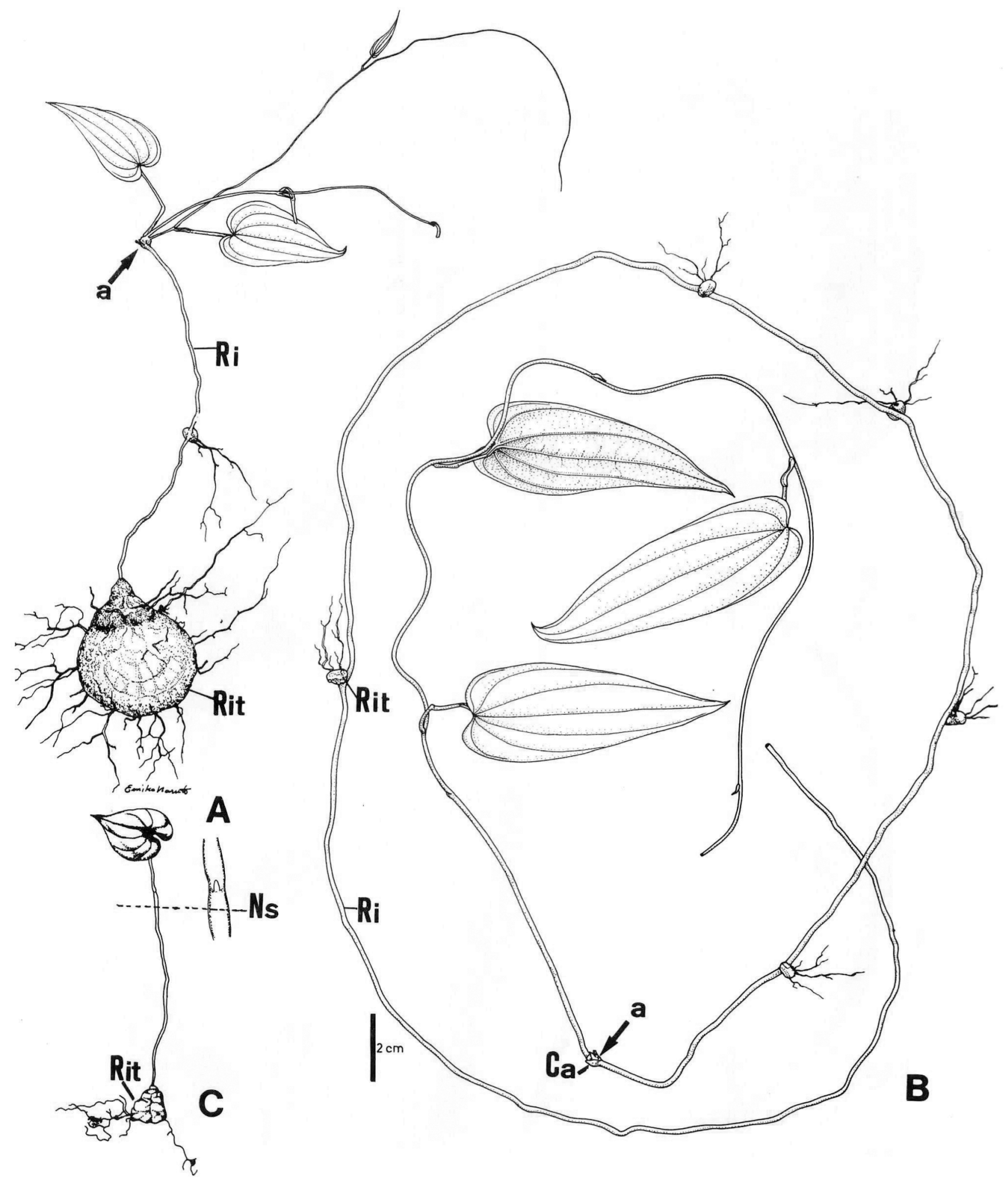

Fig. 1. Aspecto geral da planta. A- Planta jovem originada de semente; B- Parte de um exemplar de uma planta adulta contendo porção aérea (com folhas) e subterrânea; C- Planta jovem originada de um órgão espessado (Rit). A seta a indica o nó cotiledonar. Ca- catafilo; Ns- nível do solo, Ri- eixo caulinar subterrâneo (rizóforo) não espessado e Rit- eixo caulinar subterrâneo (rizóforo) espessado. (Barra $=2 \mathrm{~cm}$ )

Fig.1. General aspect of the plant with underground stem system (Ri and Rit). A-seedling. B-adult plant with thickened (Rit) and non thickened $(\mathrm{Ri})$ rhizophore. (Bars $=2 \mathrm{~cm}$ ). C- young plant from thickened rhizophore. Ca- cataphyll; Ns- ground level; Ri- non thickened rhizophore, Rit- thickened rizophore. (Bar $=2 \mathrm{~cm})$ 

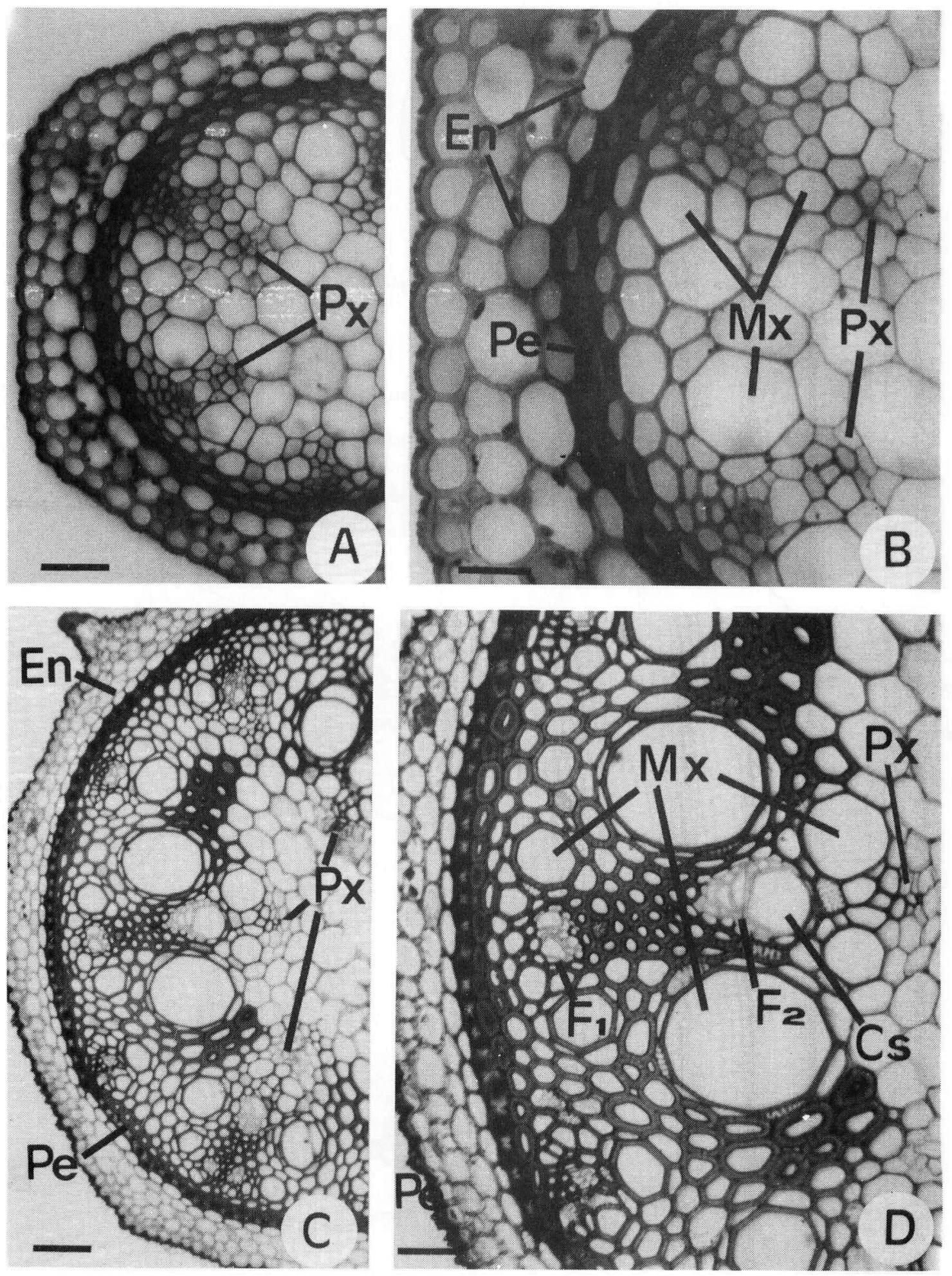

Fig. 2. Eixo caulinar aéreo. A e B-região proximal ao ápice. $\mathrm{C}$ e D- região distal do ápice. Cs- canal secretor; En-endoderme; $F_{1}-f_{10 e m a}$ externo; $F_{2}$ - floema interno; Mx-metaxilema; Pe- periciclo e Px- protoxilema. (Barras, respectivamente, 50, 25, 100 e 50um).

Fig.2. Aerial stem sections. A and B- proximal; $\mathbf{C}$ and $\mathbf{D}$ - distal region. Cs- secretory ducts; En- endodermis; $F_{1}-$ external phloem; $F_{2}-$ internal

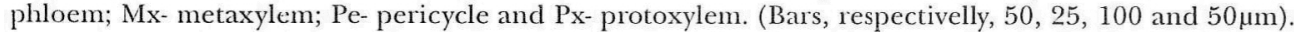



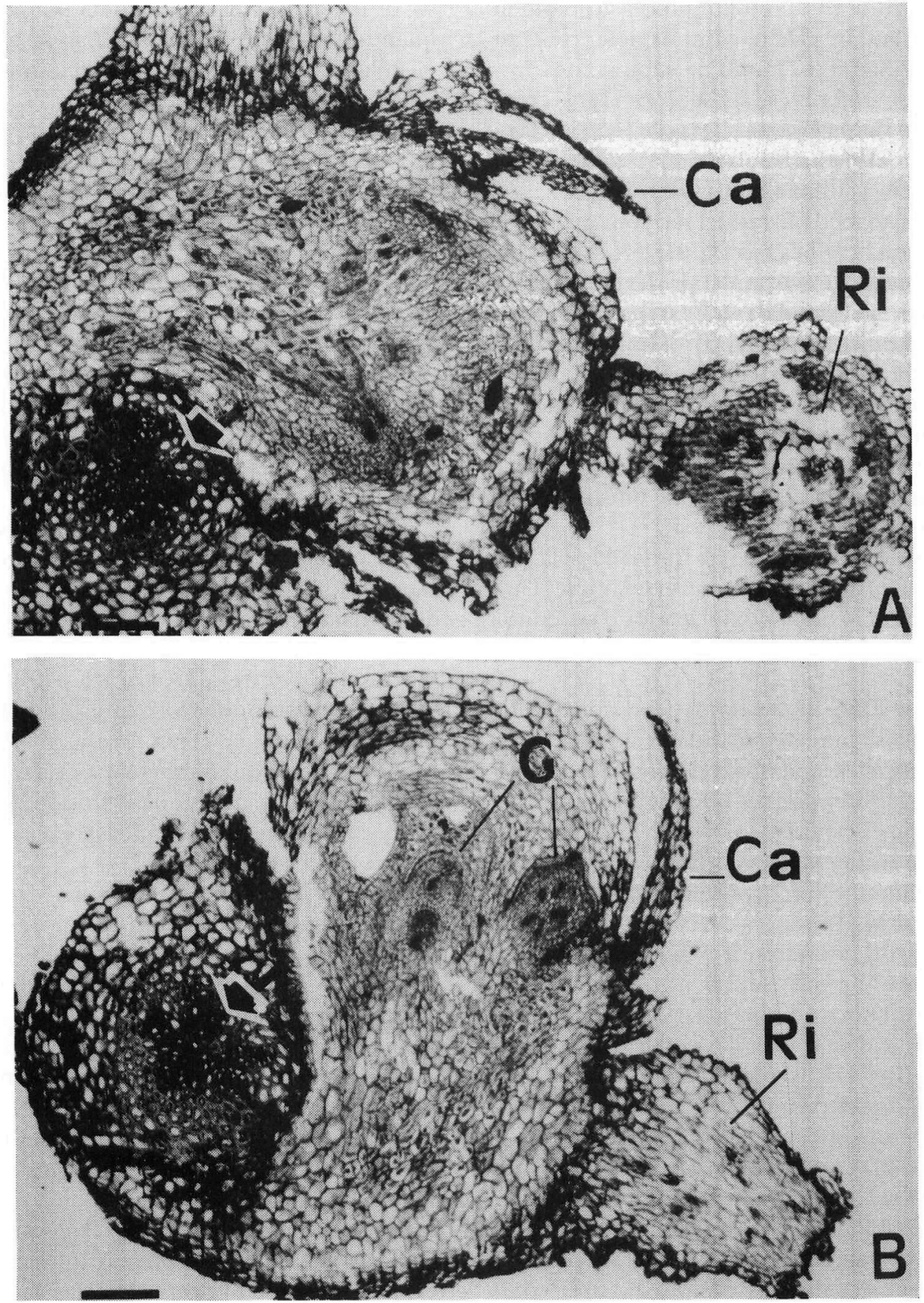

Fig. 3. A e B- Nó cotiledonar. A seta indica a base do caule aéreo. Ca- catafilo; G- gema e Ri- rizóforo não espessado.(Barras $=200 \mu \mu m)$. Fig.3. A and B- cotyledonar node. The arrow indicates the aerial stem base. Ca-cataphyll; G-bud and Ri- non thickened rhizophore. (Bars $200 \mu \mathrm{m})$. 
As setas da figura 4A apontam idioblastos contendo ráfides de oxalato de cálcio, comuns no córtex tanto na porção caulinar aérea como na subterrânea.

As figuras 5A-C referem-se às secções transversais de uma estrutura subterrânea espessada (Rit) mostradas na figura $1 \mathrm{~B}$. A seta a aponta a região onde se dá a ligação com o eixo caulinar não espessado. A seta b aponta uma gema adventícia endógena, com primórdios foliares, vista em detalhes nas figuras $6 \mathrm{~A}$ e $6 \mathrm{~B}$. Todo o conjunto está revestido por uma periderme que aparece destacada em quase toda a sua extensão devido a um artefato de técnica. A região próxima à seta b é vista em detalhe nas figuras $6 \mathrm{C}$ e $6 \mathrm{D}$. Também foram observados, em todo o conjunto, idioblastos contendo ráfides. Há acúmulo de amido no parênquima em torno dos feixes condutores e na região central do cilindro vascular dessa estrutura tuberizada, mostradas em detalhe nas figuras $5 \mathrm{~B}$ e $5 \mathrm{C}$.

A figura $5 \mathrm{~B}$ corresponde à região indicada pela seta c da figura 5A. A faixa de tecido meristemático (Tm), em destaque, é a região onde são formados o parênquima e os feixes libero-lenhosos, o início de um deles indicado pela seta.

Nas figuras $5 \mathrm{~B}$ e $5 \mathrm{C}$ notam-se os feixes, aparentemente concêntricos, mas, na realidade colaterais. A aparência concêntrica é dada pela disposição dos elementos traqueais. Observam-se, também, os raios parenquimáticos $(R)$, característicos da atividade em um meristema de espessamento secundário. O meristema se origina internamente ao córtex e externamente aos feixes vasculares primários.

As figuras $6 \mathrm{~A}$ e $6 \mathrm{~B}$ referem-se à gema caulinar endógena que está indicada pela seta $\mathbf{b}$ na figura $5 \mathrm{~A}$. Na figura $6 \mathrm{~A}$ é possível notar idioblastos (I) contendo ráfides de oxalato de cálcio na região cortical e nos primórdios foliares (Pf). Há tricomas glandulares (Tr) na epiderme adaxial desses primórdios, vistos em detalhe na figura $6 \mathrm{~B}$, comumente chamados de coléteres.

As figuras $6 \mathrm{C}$ e $6 \mathrm{D}$ correspondem a região próxima à seta $\mathbf{b}$ da figura $5 \mathrm{~A}$, onde a periderme permaneceu ligadla ao órgão. $\mathrm{O}$ felogênio $(\mathrm{Fe})$, que dá origem a esse tecido, pode ser visualizado na figura 6C. As paredes das células das camadas mais externas tornam-se completamente lignificadas, constituindo verdadeiras esclereídes (Es) com numerosos e nítidos canais de pontoações, em destaque na figura $6 \mathrm{D}$.

\section{Discussão}

O que chamou a atenção, à primeira vista, em $D$. kunthiana foi o fato desta planta apresentar vários quantidade de caracteres típicos de dicotiledôneas. Possui folhas pecioladas com venação reticuladas e estômatos do tipo anomocítico (dados não ilustrados). Além dis- so, os feixes vasculares, tanto da porção aérea do caule quanto da porção subterrânea, apresentam disposição eustélica com uma medula perfeitamente distinta nestes mesmos órgãos.

A literatura relata que desde muito cedo estas características já tinham sido observadas em outras Dioscoreales. Contudo, baseado em caracteres florais, não há dúvida de que se tratam de monocotiledôneas (Brown 1810, Knuth 1924).

Segundo Dahlgren et al. (1985) na ordem Dioscoreales observam-se vários caracteres vegetativos e reprodutivos que indicam uma relação muito estreita com as dicotiledôneas. Para eles, as monocotiledôneas se originaram a partir das dicotiledôneas e o provável ancestral das monocotiledôneas deveria apresentar muitas das características observadas nos representantes das Dioscoreaeae atuais.

Em D. kunthiana o sistema subterrâneo é notável. Na sua maioria, é de natureza caulinar. O eixo não espessado, embora frágil, pode alcançar profundidades consideráveis no solo, apresentando regiões tuberizadas que quando bem desenvolvidas evidenciam nítidos nós e entrenós. Quando se forma uma tuberosidade na extremidade terminal desse eixo, o crescimento longitudinal cessa. Dessas formações tuberizadas, e somente delas, partem as raízes favorecendo a hipótese de que uma função importante dessas estruturas caulinares subterrâneas seja a de "portadoras de raízes".

Nas porções aérea e subterrânea do caule não espessado, a disposição eustélica dos feixes vasculares, formando um cilindro central, obedece a um arranjo distinto no qual feixes maiores se intercalam com feixes menores. Segundo Burkill (1960), Ayensu (1969) e Behnke (1990) geralmente, os feixes maiores têm formato em V e são denominados caulinares enquanto os feixes menores têm formato mais elíptico e são denominados comuns. Para Teichman und Logischen e Robbertse (1981) a diferença entre eles é percebida pela disposição dos vasos de metaxilema junto às unidades de floema, sendo que os feixes comuns se localizam mais externamente e os feixes caulinares estão mais internamente no cilindro vascular. Embora não tenha sido feito um acompanhamento, acredita-se que os feixes "comuns" correspondam a traços foliares.

Lawton e Lawton (1969) já tinham notado que na porção subterrânea que se apresenta espessada, os feixes vasculares são do tipo colateral, com apenas uma unidade de floema no seu interior. Em D. kunthiana, foram observados feixes libero-lenhosos com floema dividido em duas unidades nas porções caulinares não espessadas (aérea e subterrânea) e floema único em feixes colaterais na porção subterrânea espessada.

Segundo Xifreda (1990) a disposição do floema em 

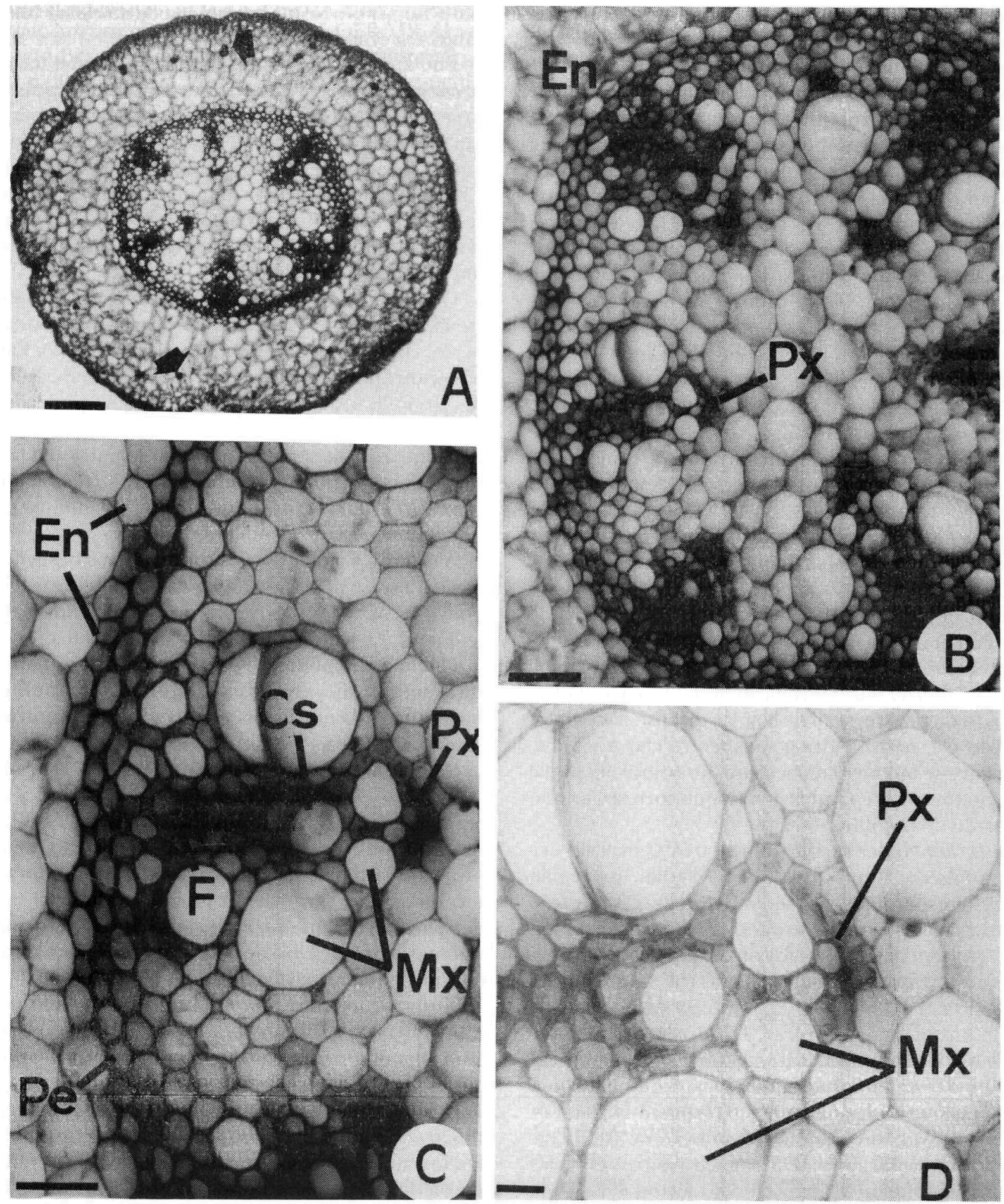

Fig. 4. A-D- Eixo caulinar subterrâneo não espessado (corresponde a Ri da Fig. 1). As setas apontam idioblastos. Cs- canal secretor; Enendoderme; F- floema; Mx- metaxilema; Pe- periciclo e Px- protoxilema. (Barras = respectivamente 250, 100, $50 \mathrm{e} 25 \mu \mathrm{m}$ ).

Fig. 4. A-D-sections of the non thickened rhizophore ( $\mathrm{Ri}$ in the Fig. 1). The arrows indicate idioblasts. Cs- secretory duct; En- endodermis; F- phloem; Mx- metaxylem; Px- protoxylem. (Bars = respectivelly 250, 100, 50 and $25 \mu \mathrm{m}$ ). 
unidades teria uma possível relação com o hábito escandente típico das Dioscoreaceae, a exemplo do que se observa em lianas dicotiledôneas.

Burkill (1960) menciona que algumas espécies de Dioscorea têm dois tipos morfologicamente distintos de órgãos de reserva, ambos de natureza caulinar, um aéreo (bulbilho) e outro subterrâneo (tubérculo). Por outro lado, Sharma (1976), estudando o bulbilho e o tubérculo em D. glabra observa que ambos têm estruturas semelhantes e considera o primeiro como sendo uma versão aérea do tubérculo, especializada como propágulo vegetativo. Segundo este autor, em D. glabra há três gemas de origem endógena (uma axilar e duas acessórias) na axila da folha. $O$ bulbilho se origina de uma protuberância desenvolvida num eixo da gema acessória. Ele reconhece, também, uma porção subaérea do bulbilho de onde surgem raízes adventícias e considera que esta porção não é nem uma mistura de caule e raiz, nem um órgão "suigeneris", como o pretende Goebel (1905).

Nwoke ( 1987), comparando as espécies D. alala, $D$. dumetorum, D. cayenensis, D. bulbiferce e D. rotundata verificou que na axila da folha existe um tipo de arranjo múltiplo de gemas axilares (variando em número de três a cinco, conforme a espécie) e observou o desenvolvimento do órgão tuberizado que aí se forma (bulbilho). Considerou que a formação desta tuberosidade é resultado da proliferação de células da base das gemas. Segundo ele, na base das gemas, entre elas e a folha, desenvolve-se um meristema chamado complexo nodal primário (primary complex nodal) que corresponde ao primórdio do bulbilho.

Em D. kunthiana verificaram-se três gemas de origem endógena, numa distribuição radial, na região nodal correspondente ao nó cotiledonar. Esta porção aćrea do caule sofre espessamento. Na porção subterrânea espessada também foram vistas gemas. Entretanto, neste caso, com outra disposição. Também foi verificado em $D$. kunthiana que o órgão espessado carece de um meristema apical. Seu desenvolvimento é devido a atividade do meristema de espessamento secundário de origem pericíclica que se apresenta como uma faixa de tecido meristemático formando feixes vasculares e tecido parenquimático de reserva. Isto já havia sido observado anteriormente para outras espécies de Dioscorea (Martin \& Ortiz, 1963; Lawton \& Lawton, 1969; Sharma, 1980). Trata-se do meristema de espessamento secundário (STM- secondary thickening meristem) de ocorrência em algumas monocotiledôneas que crescem em espessura (Rudall 1991), visto que estas não apresentam câmbio do tipo que se observa na maioria das dicotiledôneas e gimnospermas. Segundo a autora, este meristema é responsável pelo espessamento secundário em caules, pela produção de raízes ad- ventícias e pela formação de ligações vasculares entre caule, raiz c folhas.

Em D. kunthiana não há dúvidas de que o tecido de revestimento das estruturas que sofreram espessamento seja realmente periderme, pois se forma a partir de um felogênio. Este fato já havia sido constatado para outras espécies de Dioscorea por Goebel (1905), Lawton e Lawton (1969) e Teichman und Logischen e Robbertse (1981). Entretanto, Martin e Ortiz (1963) haviam notificado que em $D$. floriunda e $D$. spiculiflora ocorre um súber estratificado.

Os idioblastos contendo ráfides observados em $D$. kunthiana já foram também observados em outras espécies como comentam Martin e Ortiz (1963), Lawton e Lawton (1969) e Teichman und Logischen e Robbertse (1981). Entretanto não discutem qual poderia ser a importância disto. Martin e Ortiz (1963) apenas comentam que a planta pode estar acumulando oxalato de cálcio desta forma. Com certeza, trata-se de uma proteção contra herbivoria, já que há, no solo, muitos predadores.

A classificação de órgãos subterrâneos baseado apenas em observações morfológicas, muitas vezes foram pouco esclarecedores. A confusão se dá principalmente quando se tratam de rizomas e tubérculos.

O termo xilopódio foi utilizado para designar estruturas subterrâneas espessadas (de natureza caulinar e/ ou radicular) com determinado grau de lignificação (Lindman 1906).

Segundo a hipótese de Raunkiaer (1937) a evolução dos vegetais se deu com a finalidade de esconder e proteger as gemas para que a planta sobreviva às estações desfavoráveis. Ele sugere que tenha ocorrido uma evolução de sistemas caulinares aéreos passando a subterrâneos que, por sua vez, devido à diminuição dos entrenós tornaram-se mais e mais reduzidos formando rizomas, cormos e bulbos, nesta ordem. Este último é considerado então, o mais derivado de todos.

A distinção clara entre rizoma e tubérculo parece difícil. Quanto à função que desempenham, sabe-se que ambos podem acumular reservas. Entretanto, os tubérculos, mais que os rizomas, podem também ser considerados órgãos de propagação vegetativa. A origem do órgão seria um outro parâmetro confiável para distingui-los, uma vez que rizomas se originam da plúmula do embrião e, tubérculo, de ramos especiais originados do hipocótilo (ou menos freqüentemente, do epicótilo). Segundo Burkill (1960) os tubérculos têm crescimento vertical e limitado, enquanto os rizomas têm crescimento horizontal e ilimitado.

Ao estudarem os sistemas subterrâneos de algumas plantas do cerrado brasileiro Rizzini e Heringer (1962) notaram a grande variedade de formas e tamanhos que apresentavam e propuseram uma classificação baseada 

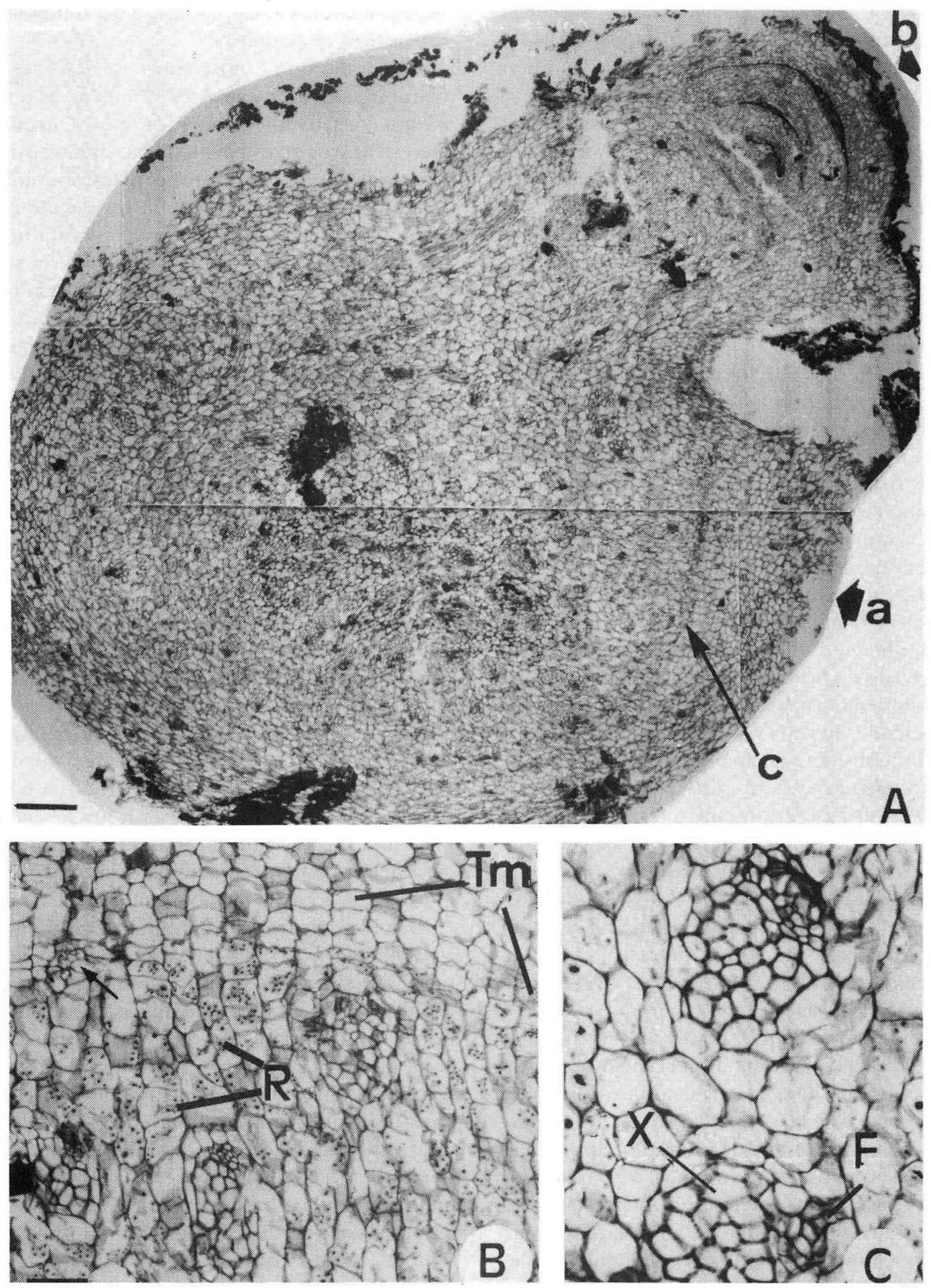

I:̈̈g. 5. A-C- Eixo caulinar subterrâneo espessado correspondente a Rit da Fig. 1. A seta a aponta a região de ligação com o eixo caulinar subterrânco não espessado; a seta b aponta uma região contendo gemas endógenas. B- detalhe da região c da figura A em que se vê o início de um feixe na zona meristemática. C- Detalhe do feixe vascular completo. F- floema; R- raio parenquimático; Tm- meristema de espessamento secundário e X-xilema. (Barras = respectivamente, 60, 100 e $50 \mathrm{~mm}$ )

Fig. 5. A-C-Thickened rhizophore (Rit in the Fig. 1). A-Arrow a indicates the region of connection with the non thickened rhizophore; arrow $\mathbf{b}$ indicates the region with endogenous bud. B- Secondary thickening meristem $(\mathrm{Tm})$ indicated by arrow $\mathbf{c}$ in figure $\mathrm{A}$ of the thickened rhizophore with a new vascular bundle (arrow). C- Two vascular bundles. F-phloem; R-ray and X-xylem. (Bars= respectivelly, 60, 100 and $50 \mathrm{~mm}$ ). 
na profundidade e extensão que alcançavam, procurando relacionar estas características com aspectos fisiológricos (condução de água). Os mesmos autores também comentam em sua discussão que é freqüente a confusão feita no emprego do termo rizoma, afirmando textualmente referindo-se aos sóboles: “...é de toda conveniência atentar para o nome duplamente impróprio de rizoma que se aplica geralmente a estes órgãos (sic) rizoma é o caule subterrâneo be'n caracterizado das monocotiledôneas...". Tais autores utilizaram o termo sóbole para designar estruturas caulinares subterrâneas de muitas dicotiledôneas analisadas. Para outras, usaram os termos raízes gemíferas e xilopódio.

Quando se trata de Dioscoreaceae, uma ampla variedade de termos é empregada para designar as estruturas subterrâneas espessadas. Degras (1986) ilustra, pelo menos, 71 formas morfológicas diferentes, na sua maioria, classificadas como tubérculos. Outros autores tratam como rizomas e uma minoria refere-se a eles como cormo, como raízes tuberizadas, armazenadoras e tuberculosas ou estoloníferas.

Estudando principalmente espécies do Velho Mundo, Burkill (1960) relata que algumas têm rizoma e outras possuem tubérculo. Ele sugere que este último seja um órgão derivado do primeiro que sofreu encurtamento seguido de aumento nas suas dimensões e conseqüente aumento no espaço de reservas para nutrientes. Desta maneira o autor considera que o órgão perde, em parte, a capacidade de penetração no solo.

Ayensu (1972) utiliza geralmente o termo tubérculo c comenta que a dificuldade de se obter órgãos subterrâneos é o principal fator para explicar a pequena quantidade de estudos morfológicos desses, em Dioscoreaceae. Ele também afirma que tais órgãos carecem de estudos anatômicos e menciona que não estão totalmente esclarecidas as relações entre esses órgãos subterrâneos espessados e as raízes.

No presente trabalho com D. kunthiana, verificou-se quc as tubcrosidades do sistema subterrâneo originamse de um eixo caulinar com geotropismo positivo que, por sua vez, deve se originar de uma gema cotiledonar c, portanto, não corresponde ao hipocótilo. Se este fosse o hipocótilo, seria observado, apenas, o crescimento em espessura desse eixo subterrâneo. A presença de caule aéreo é uma evidência de que a porção caulinar subterrânea não é um rizoma. O espessamento de determinadas porções desse eixo se dá pela proliferação de tecidos parenquimáticos e vasculares que se diferenciaram a partir de uma zona meristemática correspondente ao meristema de espessamento secundário. $\mathrm{Na}$ região mais interna, entremeando os tecidos vasculares, observa-se o acúmulo de amido nas células parenquimáticas, como ocorre em tubérculos, entretanto, essas estruturas tuberizadas já possuem raízes, mesmo estando ligadas a planta mäe, o que näo ocorrc com os tubérculos verdadeiros.

Teichman und Logischen et al. (1977) estudaram estruturas scmelhantes em $D$. cotinifolia, as quais denominaram "órgãos intermediários" pois consideraram que tais estruturas possuem algumas características de raiz e outras de caule. Os autores concluíram que "não eram raízes porque não apresentam exoderme e nem endoderme”. Também não observaram coifa no ápice, embora tenham visto estruturas unicelulares semelhante a pêlos radiculares. Por outro lado, também não as consideraram como caules, porque não observaram estômatos, formação de nós e entrenós e, nem mesmo, sinais de folhas. Todavia, verificaram que os tecidos vasculares se organizavam em feixes colaterais como num caule.

O fato de não possuir estômatos é comum em caules subterrâneos e não significa necessariamente que seja uma característica de raiz, como pretendem os autores citados acima, pois, Menezes et al. (1979) registram ausência de folhas, apenas catafilos, num tipo de caule subterrâneo presente em Vernonia (Compositae). Baseados, principalmente, na capacidade desta estrutura caulinar subterrânea apresentar crescimento geotrópico positivo e somente ela originar raízes, esses autores chamaram de rizóforo a porção caulinar do sistema subterrâneo dessa planta. Esses autores observaram, ainda, que as gemas axilares desses rizóforos quando dentro da terra, somente produziam novos rizóforos. Posteriormente, Sajo e Menezes (1986) verificaram que os rizóforos quando expostos à luz, essas gemas dão origem a ramos caulinares aéreos, com folhas. Verificaram, também, que a origem desses rizóforos em Vernonia se dá a partir do nó cotiledonar.

O termo rizóforo foi também empregado para $R i$ zophora mangle L. por Menezes (1993) que verificou tratar-se, nessa planta, de um sistema vegetativo caulinar bipolar. A autora verificou que as chamadas "raízes suporte" apresentam uma natureza estrutural caulinar contendo na extremidade um meristema capaz de desenvolver raízes adventícias ao tocar o substrato. Ela considerou portanto, que em Rizophora mangle há a mesma bipolaridade observada no sistema caulinar das Lepidodendrales fósseis, nas quais os ramos apicais formam folhas e os basais, raízes. Estes ramos basais de natureza caulinar, foram denominados, pelos paleobotânicos, como rizóforos (Stewart 1983).

Em D. kunthiana o termo rizóforo parece ser o que melhor defïne o sistema caulinar subterrâneo, espessado ou não. As raízes, sempre presentes, partem somente das porções espessadas, portanto toda a água absorvida pelas raízes da planta têm que, obrigatoriamente, passar por esses órgãos. Nesse caso então, além de serem órgãos de resistência, tais estruturas têm papel evidente na condução de água e nutrientes absorvi- 

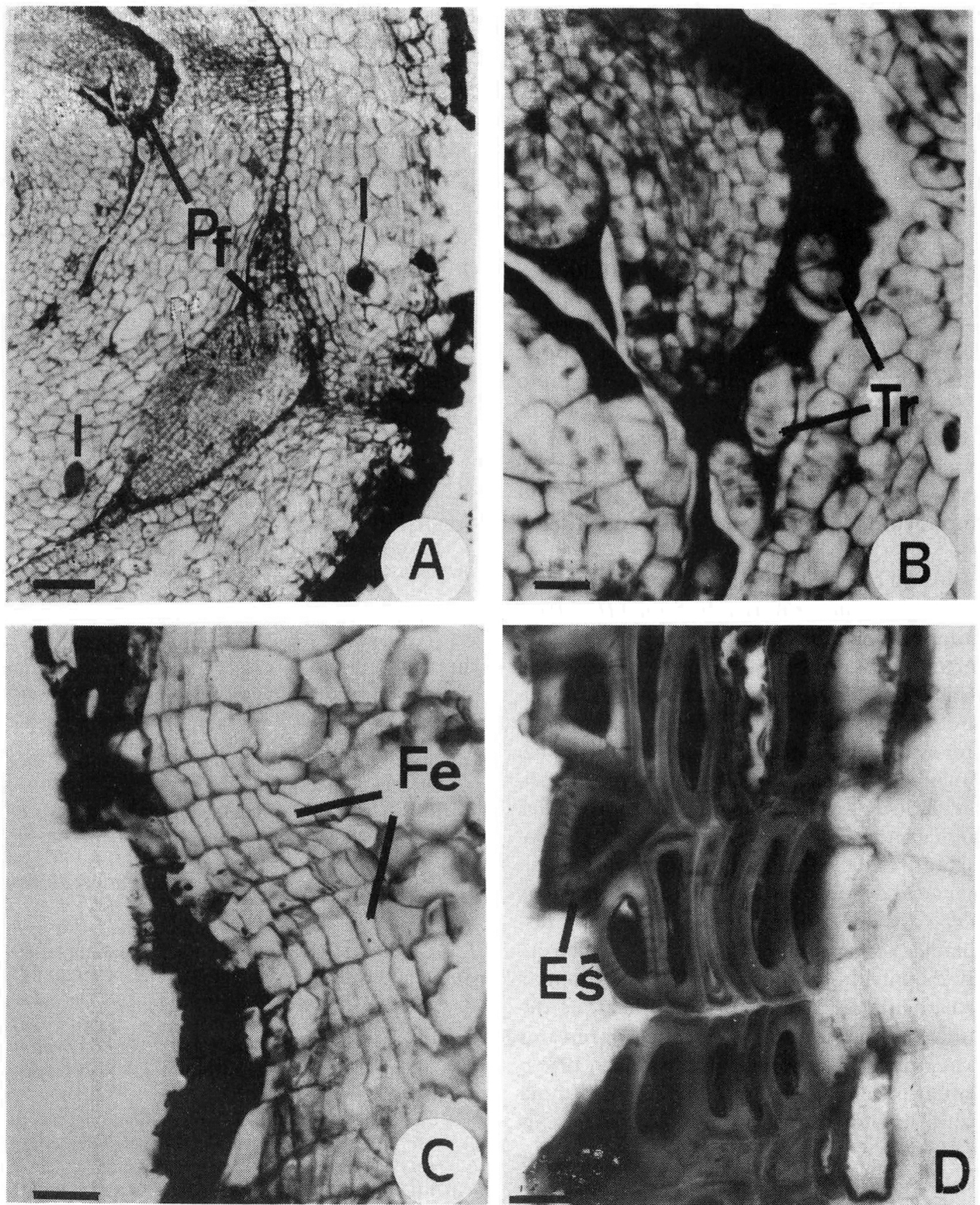

Fig. 6. A e B- Correspondem a detalhes da gema indicada na Fig. 5A. C e D- detalhes da periderme. Es- esclereíde; Fe- felogênio; I- idioblasto; Pf-primórdio foliar e Tr- tricoma. (Barras = respectivamente 100, 25, 50 and $25 \mu \mathrm{m}$ ).

Fig.6. A and B-Correspound to the bud of the figure 5A. C and D-periderm details. Es-esclereid; Fe- phellogen; I- idioblast; Pf- leaf primordium and $\mathrm{Tr}$ - trichome. (Bars = respectivelly, 100, 25, 50 and $25 \mu \mathrm{m}$ ) 
dos pelas raízes. Assim, a definição de rizóforo (o que porta raízes) foi estabelecida com o mesmo raciocínio usado para definir os órgãos subterrâneos de Vernonia e as estruturas de suporte de Rizophora mangle isto é, por homologia ao rizóforo de Selaginella.

O termo tubérculo não deve ser usado neste caso porque é próprio para definir um órgão subterrâneo de natureza caulinar cuja principal função é o armazenamento de reservas quando ligado à planta mãe. Somente quando isolado desta, produzirá raízes, tornando-se então, um órgão de propagação vegetativa.

O termo rizoma também não deve ser empregado porque uma mesma planta que possui rizoma não pode apresentar um outro sistema caulinar aéreo. Segundo Raunkiaer (1937) Rizzini e Heringer (1966), e Strasburger (1963) entre outros que se preocuparam com as formas de vida apresentadas pelas plantas, o rizoma é um sistema vegetativo, único, que pode ser encontrado em muitas monocotiledôneas e em algumas dicotiledôneas.

Goebel (1905) já havia relacionado os órgãos subterrâneos de Dioscorea com rizóforos de Selaginella. Para ele as estruturas tuberizadas de diferentes espécies de Dioscorea pertencem a um grupo de órgãos extraordinários, pois são considerados, em parte, ora como raízes, ora como ramos caulinares. Admite ainda, que tais órgãos seriam estruturas de transição entre caule e raiz, ou ainda, uma neoformação. Ressalta também, a considerável capacidade de regeneração que estas formações apresentam. Segundo esse autor, esses órgãos são, sobretudo, portadores de raízes, isto é, órgãos que possibilitam a formação de um sistema radicular muito mais rico em relação aos que, normalmente, estariam à disposição da planta. Seguramente, a obra de Goebel trouxe uma grande contribuição para o estudo de sistemas caulinares e radiculares, propondo uma idéia que deveria ter mudado e, em muito, o conceito sobre estes dois sistemas.Como afirmaram Groff e Kaplan (1988), é de se lamentar que a maioria dos trabalhos de língua inglesa deixem de citar obras em alemão, particularmente as de Goebel.

Uma dificuldade encontrada na avaliação da bibliografia apresentada, foi a falta de ilustrações detalhadas da morfologia externa dos órgãos subterrâneos das Dioscoreaceae que, à exceção daquelas feitas por Goebel (1905), deixam muito a desejar quanto à disposição das raízes. Desta maneira, afirmar com segurança, para outras espécies do gênero Dioscorea, que os órgãos considerados tubérculos são, na realidade, rizóforos, não é possível sem antes observá-los in vivo.

Quando ocorre uma reprodução vegetativa como mostrado pela figura $1 \mathrm{C}$, dá-se o crescimento de um sistema caulinar com as mesmas características anatômicas do eixo não espessado do rizóforo, isto é, acloro- filado e com o córtex levemente mais espessado que a parte aérea do caule. No entanto, não se observam os catafilos e o desvio do eixo como se vê nos exemplares $1 \mathrm{~A}$ e $1 \mathrm{~B}$.

No presente trabalho, verificaram-se muitos problemas referentes aos órgãos subterrâneos cuja resposta ainda é desconhecida e que merecem ser esclarecidos, tais como i) Como se realiza o crescimento do eixo subterrâneo em $D$. kunthiana? ii) O que ocorre com o hipocótilo e com a raiz primária após a germinação da semente? iii) Qual seria o papel do rizóforo no conceito de evolução dos sistemas caulinares subterrâneos? Estas perguntas poderão ser o início para novos estudos.

\section{Bibliografia}

AYENSU, E.S. 1969. Aspects of the complex nodal anatomy of the Dioscoreacceae. J. Arnold Arbor. 50: 124-137.

AYENSU, E.S. 1972. Anatomy of the monocotyledons. VI. Dioscoreales. Oxford Univ. Press. London.

BARROSO, G.M.; SUCRE, D.; GUIMARÃES, E.F.; CARVALHO L.F.; VALENTE, M.C.; SILVA, J.D.; SILVA, J.B.; ROSENTHAL, F.R.T., BARBOSA. C.M.; ROSEIRA, A.N.; BARTH, O.M. \& BARBOSA, A.F. 1974. Flora da Guanabara. Sellowia 25: 9-256.

BEHNKE, D.H. 1990. Sieve Elements in Internodal and nodal anastomoses of the monocotyledons liana, Dioscorea. In Behnke \& R.D. Sjolund (Eds.) Sieve Elements Comparative structure, induction and development. Spring-Verlag. Berlin.

BROWN, R. 1810. Dioscoreae. Prodromus Florae Novae Hollandiae, 294-295. London.

BURKILL, H.I. 1960. The organography and the evolution of Diocoreaceae, the family of the yams. Bot. J. Linn. Soc. 56: 319-412.

CHU, E.P. \& FIGUEIREDO-RIBEIRO, R.C.L.1991. Native and exotic species of Dioscorea used as food in Brazil. Econ. Bot. 45 (4): 467-479.

CORREAA, M.P. 1926. Dicionário das plantas utéis do Brasil e das exóticas cultivadas. vol. II. Imp. Nac. do Rio de Janeiro.RJ.

DAHLGREN, R.M.T.; CLIFFORD, H.T. \& YEO, P.F. 1985. The families of the monocotyledons, structure, evolution and taxonomy. Springer-Verlag. Berlin.

DEGRAS, L. 1986. L'igname. Plante a tubercle tropicale. Techniques agricoles et productions tropicales. XXXVI. Paris G.P. Maisonneuve et Larose. Paris.

FIGUEIREDO, R.C.L. 1971. Sobre a anatomia das partes vegetativas de Ocimum nudicaule Benth. (Labiatae). An. Acad. Bras. Ciênc. 44: 549-570.

GIULIETTI, A.M.; MENEZES, N.L.; PIRANI, J.R.; MEGURO, M. \& WANDERLEY, M.G.L. 1987. Flora da Serra do Cipó, Minas Gerais: Caracterização e lista das espécies. Bol. Bot. Univ. São Paulo 9: 1-151.

GOEBEL, K. 1905. Morphologische und biologische bernerkungen. 16. Die Knollen der Dioscoreen und die Wurzelträger der Selaginellem, organe, welchezwischen wurzeln und sprossen stehen. Flora 95: 167-212.

GROFF, P.A. \& KAPLAN, D.R. 1988.The relation of root systems to shoot systems in vascular plants. Bot. Rev. 54(4):387-422.

JOHANSEN, D.A. 1940. Plant microtechnique. McGraw Hill Books Co. New York.

KNUTH, R. 1924. Dioscoreaceae. In A. Engler (ed.) Das Pflanzenreich IV. 43. Wilhelm Engelmann. Leipzig, p. 1-387.

LADEIRA, A.M.; CHU, E.P.; MAYWORM, M.A.S. \& FIGUEIRE- 
DO-RIBEIRO, R.C.L. 1992. Seeds of Dioscorea delicata and D. olfersiana:germination and reserve compounds. Hohenea 19(1/ 2): $135-142$.

LAGERON, M.1949. Précis de microscopie. Masson et Cie Editeus. Paris.

LAWTON, J.R. \& LAWTON, F.L.S. 1969. The development of the tuber in seedling of five species of Dioscorea from Nigeria. Bot. J. Linn. Soc. 62: 223-232.

LINDMAN, C.A.M. 1906. A vegetação no Rio Grande do Sul (Brasil Austral). (trad. A. Loefgren). Porto Alegre.

MARTIN, F.W. AND ORTIZ, S. 1963. Origin and anatomy of tubers of Dioscorea floribunda and D. spiculiflora. Bot. Gaz. 124:416421.

MENEZES, N.L.1993. An alternative interpretation of the "supporting roots" of Rizophora mangle L. XV International Botanical Congress Abstract p. 355. Yohahama, Japan.

MENEZES, N.L.; HANDRO, W. \& MELLO CAMPOS, J.F. 1969. Estudos anatômicos em Pfaffia jubata Mart . Bol. F.F.C.L. USP (Bot) 24: 195-210.

MENEZES, N.L. ; MÜLLER, C. \& SAJO, M.G. 1979. Um novo e peculiar tipo de sistema subterrâneo em espécies de Vernonia da Serra do Cipó (MG-Brasil). Bol. Bot. Univ. São Paulo 7:33-38.

NWOKE, F.I.O. 1987. Axillary buds and vegetative propagation of Dioscorea. In E.R. Terry, M.O. Alero \& O.B.Arene (Eds.) Tropical root crops. Inter. Development Research Centre Ottawa.

PAVIANI, T.I. 1972. Estudos morfológicos e anatômicos de Brasilia sickii. G.M.Barroso. I . Revista Brasil. Biol. 32(4):45-72.

RAUNKIAER, C. 1937. Plant life forms. (trad. H.G.Carter). Oxford Clarendon Press. London.

RIZZINI, C.T. 1965. Estudos experimentais sobre xilopódio e outros órgãos tuberosos de plantas do cerrado. An. Acad. Bras. Ciênc. 37(1): 187-113.

RIZZINI, C.T.\& HERINGER, E.P. 1962. Studies on the underground organs of tree and shrubs from southern Brazilian savanna . An. Acad. Bras. Ciênc. 34(2): 235-248.

RIZZINI, C.T.\& HERINGER, E.P. 1966. Estudos sobre os sistemas subterrâneos difusos de plantas campestres. An. Acad. Bras. Ciênc.38 (Supl.): 85-111.

RUDALL, P. 1991. Lateral meristems and stem tickening growth in monocotyledons. Bot. Rev. 57(2): 150-161.

SAJO, M.G. \& MENEZES, N.L. 1986. Origem e crescimento do rizóforo em espécies de Vernonia Screb. (Compositae), da Serra do Cipó, MG. Revista brasil. Biol. 46 (1): 197-202.
SILVER, V.L. \& PRICE, J. L. 1969. Demostration of calcium oxalate crystals in plant tissues by the Pizzolato $\left(\mathrm{AgNO}_{3} \mathrm{H}_{2} \mathrm{O}_{2}\right)$ method. Stain Technology 44 (5):257-259.

SHARMA. O.P. 1976. Tuber versus bulbil of Dioscorea glabra origin, development, sprouting and morphology. Phytomorpho. logy 26:87-96.

SHARMA. O.P. 1980. Ontogeny and morphology of the tuber of Dioscorea floribunda Mart. et Gal. Proc. Indian Acad. Sci. 89 (1): 47-55.

SOUZA, H.C.; LUQUE, R. \& KRAUS, J.E. 1995.Revisão e padronização das metodologias de dupla coloração com azul de astra ou azul de alcian versus fucsina básica ou safranina. Resumos do XLVI Congresso Nacional de Botânica, Ribeirão Preto, SP. p. 32

STEWART, W.N. 1983. Paleobotany and the evolution of plants. Cambridge Univ. Press. Cambridge.

STRASBURGER, E.1963. Tratado de Botánica. (trad. O. de Bolós). 5a. ed. Marín SA Ed. Barcelona.

TEICHMAN UND LOGISCHEN, I.; ROBBERTSE, P.J. \& van der SHIJF. 1977. The subterranean organs of Dioscorea cotinifolia Kunth: 1. germination, development, morphology and vegetative reproduction of the tuberous swollen and cilindrical intermediary organs. J.S. African. Bot. 43: 41-56.

TEICHMAN UND LOGISCHEN, I. \& P.J. ROBBERTSE. 1981. The subterranean intermediary organs of $D$. cotinifolia Kunth: 2. anatomy of these organs in comparison with that of a typical root and shoot. J.S.African Bot. 47: 637-651.

VIANNA, A.M. \& FELIPPE, G.M. 1984. Crescimento foliar de Dioscorea composita. An. IV Cong. SBSP: 47-64.

VIANNA, A.M. \& FELIPPE, G.M..1986. Efeitos de luz e temperatura na germinação de Dioscorea composita. Revista Brasil. Bot. 9: 109-115.

VIANNA, A.M. \& FELIPPE, G.M..1990. Effects of storage on germination of Dioscorea composita (Dioscoreaceae) seeds. Econ. Bot. 44: 311-317.

VIANNA, A. M. \& MANTEL, S.H. 1989. Callus induction and plant regeneration from excised zygotic embryos of the seed propagated yams $D$. composita Helmsl and D. cayenensis Lam. Plant Cell, Tissue Organ Culture 16: 113-122.

XIFREDA, C.C. 1990. Observaciones sobre histologia caulinar en Dioscorea multiflora (Dioscoreaceae). Darwianna 30(4): 11-19.

WICKHAM, L.; WILSON, L.A. \& PASSAN, H.C. 1981. Tuber germination and early growth in four edible Dioscorea sp. Ann. Bot. 47: 87-95. 